\title{
MEMORIAL DO PROFESSOR NILTON BUENO FISCHER
}

\author{
TEACHER NILTON BUENO FISCHER'S MEMORIAL \\ MEMORIAL DEL PROFESOR NILTON BUENO FISCHER
}

Gustavo Daudt Fischer*

fischer.gustavo@gmail.com

Janaína Daudt Fischer**

ina.janainafischer@gmail.com

RESUMO: O presente texto foi gerado a partir de cópia impressa encontrada entre diversos materiais preservados por Gustavo e Janaina, filhos do professor Nilton Bueno Fischer, após seu falecimento em julho de 2009. Embora escrito em 1993, o texto, por tratar-se de um memorial, apresenta um relato em que lembranças afetivas se entrelaçam a uma sensível visão do professor Nilton sobre o campo da educação e seu potencial transdisciplinar e transformador que o fez levar adiante por mais tempo (ainda que tão pouco!) tantas iniciativas dentro e fora dos muros da universidade. Inferimos que talvez não seja uma versão completamente revisada por ele, mas ainda assim optamos por reproduzir ao máximo o texto no original.

Palavras-chave: Educação. Memorial. Lembranças afetivas. Transdisciplinaridade. Transformação

ABSTRACT: The following paper was engendered from a printed copy found among the materials preserved by Gustavo e Janaina, after their father, Nilton Bueno Fischer, died in July, 2009. Despite being written in 1993 , as a memorial, the text reports emotional memories overlapped to a sensitive view about the educational field and its transdisciplinary/transforming potential, which made Nilton take initiatives forward in and out the University walls. Although it may be a non-reviewed by Nilton version we chose to fully play it in the original paper.

Keywords: Education. Memorial. Affective memories. Transdisciplinary. Transformation.

RESUMEN: El presente texto fue producido a partir de una copia impresa encontrada entre diversos materiales preservados por Gustavo y Janaina, hijos del profesor Nilton Bueno Fischer, tras su muerte en julio de 2009. Aunque escrito en 1993, el texto por tratarse de un memorial, presenta un relato en que los recuerdos afectivos se entrelazan a una sensible visión del profesor Niltonacercadel campo de la educación y su potencial transdisciplinar y transformador que lo hizo llevar adelante por más tiempo (aun que tan poco!) tantas iniciativas dentro y fuera de los muros de la Universidad. Inferimos que tal vez no sea una versión completamente revisada por él, pero aun así elegimos reproducir al máximo el texto en el original.

Palabras clave: Educación. Memorial. Recuerdos afectivos. Transdiciplinariedad. Transformación. 
* Professor na área de Comunicação na Unisinos.

${ }^{* *}$ Roteirista.

\section{NOTA DE INTRODUÇÃO}

O presente texto foi gerado a partir de cópia impressa encontrada entre diversos materiais preservados por Gustavo e Janaina, filhos do professor Nilton Bueno Fischer, após seu falecimento em julho de 2009. Embora escrito em 1993, o texto, por tratar-se de um memorial, apresenta um relato em que lembranças afetivas se entrelaçam a uma sensível visão do professor Nilton sobre o campo da educação e seu potencial transdisciplinar e transformador que o fez levar adiante por mais tempo (ainda que tão pouco!) tantas iniciativas dentro e fora dos muros da universidade. Inferimos que talvez não seja uma versão completamente revisada por ele, mas ainda assim optamos por reproduzir ao máximo o texto no original. $\mathrm{O}$ trabalho de nova digitação e formatação foi realizado no quarto do menino Davi, pelos seus pais, enquanto o neto do professor Nilton, às vésperas de completer seu primeiro ano de vida, dormia.

\section{MEMORIAL: POR NILTON BUENO FISCHER EM 1993}

Apresentado para o Concurso de Titular na área de Fundamentos da Educação do Departamento do Estudos Básicos (DEBAS) da Faculdade de Educação (FACED) da Universidade Federal do Rio Grande do Sul (UFRGS), 1993.

\subsection{Começo pelo começo}

Nascido lá nos campos de Dom Pedrito tive um ambiente bem próximo daquilo que viria a ser minha vida profissional. Nasci no tempo em que se nascia em casa. Literalmente. Até hoje carrego na certidão de nascimento, "local: em seu domicílio".

E, por ironia, onde se localizava esse domicílio? Precisamente num sobrado, que ainda hoje existe, situado na quadra principal daquela cidade onde estão o prédio da Prefeitura Municipal, a Igreja Matriz, o Clube dos Caixeiros Viajantes e, precisamente, ao lado do Colégio Nossa Senhora do Patrocínio. O detalhe importante é que meu pai, saindo do Seminário lá de Bom Princípio, tinha arranjado emprego nesse colégio a convite de um Padre, alemão, da ordem dos Oblatos, que veio até Porto Alegre, em 1945, em busca de um professor de Latim, Português e outras disciplinas. Meu pai, sem conhecer nada daquela cultura da fronteira, aceitou o desafio e, para aumentar a sua renda, também iniciou suas atividades como secretário do colégio. A secretaria não era nada mais nada menos que localizada na sala do tal sobrado onde nasci. Em outras palavras, me criei já cercado de professores, alunos e papéis relacionados com os registros escolares. Para completar, minha mãe era professora estadual, do Colégio Bernardino Ângelo. Vale lembrar que o pai e a mãe se conheceram durante os 
festejos comemorativos do final da II Guerra Mundial, em plenas escadarias do prédio da Prefeitura, cada um trazendo seu discurso representando suas instituições escolares. No caso, era o pai como professor e secretário e a mãe como aluna do "complementar" do colégio Nossa Senhora do Horto.

Minha alfabetização começou em casa com minha mãe, onde iniciei meu primeiro ano letivo, vindo a completá-lo na Escola São Luiz, já em Novo Hamburgo, no segundo semestre de 1954. Tenho ainda na memória as aulas recebidas em casa, os temas que tinha de fazer e a mãe sempre me ensinando com as exigências normais requeridas na escola. Também tenho ainda claro como foi meu exame de adaptação ao colégio das freiras, quando tive que fazer uma prova, sozinho, de leitura, ditado e cópia.

Os tempos em Dom Pedrito foram muito bonitos. Não entendia bem ainda como se processavam tantos nascimentos em casa! Só sei que tinha quase sempre uma novidade em cada ano, ou no máximo a cada ano e meio, de mais um irmãozinho que chegava ao mundo. Entre fevereiro de 1947 e junho de 1954, nasceram seis! Depois, já em Novo Hamburgo, outros seis vieram entre esse período e o ano de 1967. Esse processo educativo que acontecia em casa, exigindo uma permanente convivência com irmãos menores, tendo que cuidar em sempre estar dividindo não só o indispensável carinho, mas também alimento e roupa, oportunizou uma formação muito especial pra mim.

A reflexão sobre o passado necessariamente nos provoca sentimentos nostálgicos, fazendo com que os fatos venham à tona de forma um tanto romântica. Isso, entretanto, não nos impede de perceber as marcas significativas, que ficaram para sempre. $\mathrm{O}$ adjetivo bonito acima indicado me faz recordar que, além de aprender em casa as primeiras letras, eu tinha especial gosto em ajudar a mãe nos seus livros de chamada. Explico melhor: naquela época os livros eram livros de chamada e não as "folhas" que hoje usamos. Tinham capa dura, folhas bem impressas, os nomes dos alunos eram lançados à mão, e com a letra muito torneada que a mãe tinha (e tem!), e era nesses livros que eu fazia, com lápis vermelho bem suave, o preenchimento das colunas dos dias não letivos (domingos e feriados). Um outro episódio se relacionava com o padeiro que todos os dias trazia pão e bolachas lá pra casa. Ele fazia desafios para mim, para o Flávio, o segundo irmão na escala dos 12, para a prima Diva e a Ada, menina adotada por minha avó, que consistia em lermos e também escrevermos nos papeis que embrulhavam os pães entregues. Sei que não venci o desafio, pois os outros foram mais espertos e eu copiei de um deles algumas palavras. $\mathrm{O}$ padeiro também se tornava um avaliador. Também o que não perdi foi o gosto pelos tais de "biscotos (sem o i) d agua" como minha avó Emiliana chamava!

Como já disse anteriormente, a família mudou-se para Novo Hamburgo, mas as aprendizagens pela via doméstica continuaram sendo inúmeras. Poderia fazer uma 
descrição detalhada de como preparar uma mamadeira de nenê, inclusive com o controle da temperatura do leite através de pequenos pingos no braço e indo até o lavar fraldas, passando por sua secagem atrás, por cima e até quase junto dos canos internos da chaminé! Varrer, lavar o chão, preparar comida: tudo isso fazia parte da rotina lá de casa tendo em vista os 12 filhos e o pai trabalhando em três empregos diferentes: de manhã no escritório como advogado, de tarde no Banco do Brasil e de noite como professor de Português e Latim em escolas públicas do Estado. A mãe, como professora pública, ainda lhe "sobrava" tempo para lecionar em escolas particulares, às vezes por cedência e outras tantas para gerar mais renda para essa enorme família. O que ainda aumentava as nossas responsabilidades, e por consequência, mais aprendizagens, devido aos compromissos que ambos tinham nos finais de semana: cursos para noivos e cursos de catequese, estes últimos de responsabilidade da mãe e, é claro, voluntários.

A permanente necessidade de dividir bens materiais e espirituais em casa era compensada por um ambiente que favorecia a leitura, a pesquisa e o acesso a informações a partir do conjunto de livros, revistas e outros materiais que chegavam em casa por correio. Na casa de meus pais aqui em Porto Alegre, ainda hoje existem os exemplares da Enciclopédia Labor, edição de 1955, Barcelona, escrita em Espanhol, cujos volumes eram densos de informações e com representações gráficas de primeira qualidade. Tanto esses exemplares como os da Coleção Sei e Creio, vejam o subtítulo: Enciclopédia do Católico do Século XX, edição de 1962, e mais outros exemplares de outras coleções que não recordo o nome, serviram muito para desde pequeno gostar dessas publicações. Recordo-me como tais referências me foram úteis no primeiro grau, mas especialmente no segundo, quando já frequentava uma escola pública noturna e trabalhava durante o dia. O tipo de dado e sua profundidade estavam na medida para quem já iniciava uma vida profissional desde cedo. No meio de tantos textos, meu pai recebia por correio material de alguma maneira relacionado com sua trajetória católica e assim tinha acesso, por exemplo, ao jornal $O$ Catolicismo da TFP, e eram esses textos, combinados com os da Aliança Para o Progresso (IBAD-Instituto Brasileiro de Ação Democrática), que começaram a provocar, por paradoxal que possa parecer, alguma sensibilidade para a análise da sociedade e suas relações com o ser católico. O cenário não se restringe ao fato de ter acesso a esse tipo de literatura, mas sim inclui um processo de discussão com os colegas de sala de aula e das vizinhanças.

Essas leituras davam certo apoio ao tipo de formação católica que recebia em casa, mas, ao mesmo tempo, traziam certo moralismo que não entendia muito bem, especialmente no que se refere aos ideários do nacionalismo, misturados com o trabalhismo que meus colegas de aula me passavam. Lembro como foi difícil aceitar o fato de 
um dos meus melhores amigos ter rasgado a propaganda política que estava afixada na porta de minha casa na qual constava a fotografia do General Juarez Távora. E ele, o meu melhor amigo da época, Hilton Barreto Orengo, vinha com suas falas a favor de Getúlio e do velho PTB. Aos poucos, esse processo de conviver com oposições ao que a gente pensa e que nossos amigos mais de perto discordam foi se consolidando, não sem choques, pelos anos que tive de escola, especialmente nas aulas onde tínhamos as sessões semanais dos saudosos "Grêmios Literários". Podemos ter muitas críticas ao sistema que os Maristas empregavam, ao menos o que alguns deles passavam, mas posso testemunhar o quanto esse período de criança e adolescência foram bem aproveitados através dessas aulas. Quando já no segundo grau noturno, em escola pública, o aprendizado era outro. E isso foi pra mim muito especial. Sair de uma escola onde a faixa etária era mais ou menos a mesma, alunos provenientes de classe média e até alguns internos de origem mais rica, e ir estudar com colegas que já eram pais e mães, trabalhando com muito mais intensidade e por real necessidade, permitia uma compreensão diferenciada do que representava ter tempo para estudar! Talvez não tivesse a riqueza da discussão sobre algum fato que a literatura trazia, no tempo dos grêmios literários da escola marista, mas agora era entender os desafios que a realidade do aluno-trabalhador, e do ensino noturno, trazia para o espaço da sala de aula. E eram os anos pré e pós golpe militar. Daí deu para entender melhor as outras leituras que meus colegas antigos faziam a respeito dos textos da Aliança Para o Progresso. Foi muito enriquecedor ver o quanto que também na vida de alguns professores a ditadura causou prejuízos. No segundo ano científico, em 1964, tivemos 7 (sete) professores de Física! Tudo porque o melhor, o velho e ousado professor Parreira, tinha sido cassado. Não dá para esquecer a maneira como ele dava aula. Era um estilo muito falante fazendo dos conceitos chatos da física explicações vinculadas com o nosso dia a dia. Tinha uma ironia muito fina. Sabia detectar nossas "colas" sem qualquer punição pública, pois bastava ver suas anotações nas "sabatinas" dos diversos colegas que trabalhavam em grupo... durante a prova.

Um começo de memorial e nele privilegiei aquilo que de perto se relacionava com minha trajetória de ser aluno aprendiz, nos espaços mais clássicos que constituem a escola. Vou deixar mais para o final uma reflexão sobre o quanto nesse mesmo período se constituía uma opção no terreno do afeto, a qual foi extremamente decisiva na minha vida.

\subsection{Ser pago para estudar: um antigo sonho}

Desde o segundo ano científico e durante todo o curso de graduação em Economia na Unisinos, tinha a vontade de ter tempo para estudar sem precisar trabalhar. Como 
isso era impossível, filho mais velho de 12, foi durante o mestrado quando pude realizar em parte esse sonho. Ganhei uma bolsa da Capes e, como diretor de escola comunitária na época, pude reduzir o meu salário e parte da dedicação à escola, tendo em vista o auxílio recebido e assim pude me dedicar ao estudo no mestrado.

Mas havia outro sonho junto com esse: era o de estudar e poder viajar para outro país. Uma das explicações que eu me dava era poder melhor me qualificar para poder servir aos outros e ajudar numa mudança da sociedade. O sonho, o país desejado, era a França, estudar sociologia ou algo parecido em Paris. A variável que determinou trocar Paris pela Califórnia foi a presença do meu orientador de mestrado, Ray Arthur Chesterfield que, como bom americano - pragmático - e californiano, me sugeriu que tentasse estudar nos Estados Unidos, em Stanford ou na UCLA, em Los Angeles. Pelas facilidades do inglês, em comparação com meu precário Francês, e "estudando e conversando" com ele e sua esposa (Kathy) o tempo todo, aqui no tempo no mestrado, pude me habilitar a ser estudante de doutorado no exterior. O fato de ir para Stanford foi a glória... Por quê? Por uma simples razão de encontrar interlocução com um possível e futuro orientador, Martim Carnoy, o qual, apesar de ser Americano, tinha algumas ideias mais sociais (!) e também possuía algumas ligações com o Brasil e a América Latina (ele deu guarida para muitos professores e intelectuais chilenos quando do golpe militar de 1973).

Não é possível deixar de lado a outra preocupação que eu tinha: emprego. Começa a ficar claro que o campo profissional, em Novo Hamburgo, assim como a busca de um trabalho intelectual mais de pesquisa e de assessoria dos movimentos sociais e populares estava ficando restrito. A combinação entre estudar, ser bolsista, ir ao exterior e a quase garantia de um emprego melhor (condições de trabalho e salário mais estável) foram decisivas para cursar o doutorado em educação. Lembro que ainda havia na UFRGS uma legislação interna, uma espécie de resolução que favorecia ao candidato a estudar no exterior, uma vaga garantida quando de sua volta. Assim, mesmo tendo uma bolsa do CNPq, recebi um valor mensal ínfimo, mais ou menos $10 \%$ do valor dessa bolsa e assinei um contrato no qual me obrigava, quando completado o curso, a trabalhar nesta Universidade. Era tudo o que eu queria. Estudar, ter bolsa, estar no exterior e ter emprego na minha volta.

Vale lembrar que a obtenção da Bolsa do CNPq não se constituiu num processo simples. A conjuntura política nacional estava mais para controle do que para democracia. Na minha ficha de bolsista tinha um último item no qual constava a pergunta sobre filiação partidária! Quem poderia imaginar a extensão do controle ditatorial. Ao mesmo tempo tentava arranjar os papéis para meu passaporte e um dos documentos exigidos era o famoso atestado de bons antecedentes que era fornecido pelo Dops. 
E qual não foi a minha surpresa quando recebi, em novembro de 1976 (dia 3), uma resposta trágica no guichê do "palácio da polícia": "o Sr. não poderá receber esse documento tendo em vista o que consta em sua ficha! A solução é o senhor prestar depoimento no cartório." Vale registrar os dois sentimentos que tive no momento: o primeiro de indignação frente ao inusitado de não poder receber o tal atestado e, o segundo, o alívio pelo fato que tinha (tenho) um irmão que trabalha em cartório, em Novo Hamburgo, e assim, pensava eu, poderia ir lá e fazer uma declaração e tudo estaria resolvido. Mal sabia eu que existiam dois cartórios DENTRO do dito palácio da polícia e que era lá onde eu deveria prestar meu depoimento. Bem, o que fazer? Fui pedir ajuda para as pessoas que além de minhas amigas já tinham passado por semelhante situação. Foi assim que cheguei até a presença do então presidente do CPERS, Prof. e advogado, Hermes Zanetti. Ele foi recomendado por minha tia, Rafaela, tendo em vista seu auxílio aos seminaristas de Viamão com problemas políticos. Valeu, valeu muito. Ele me instruiu assim: não responda não! Aceite, em princípio, (obviamente se for pertinente) a direção da pergunta, mas faça pequenos contornos... E assim fui, em 14 de fevereiro de 1977, para o interrogatório. Entre as 17 perguntas destaco duas: "o Sr. pregou ideias socialistas durante seus estudos de economia lá na Unisinos?" "Sim, mas como parte de meus estudos da disciplina 'Sistemas Políticos Comparados' na qual um grupo estudava os países capitalistas, um outro os países do $3^{\circ}$ mundo e o outro grupo os países socialistas." E o interrogador continuou: "Mas aqui consta que o Sr. falava dessas ideias em público e em voz alta." Respondi que isso era parte normal do desempenho em sala de aula, pois cabia apresentação pública dos trabalhos em grupo. Claro que os termos devem ter sido diferentes (minha memória tem pouco registro daqueles momentos de tensão). A outra pergunta foi: "O Sr. tem ideologia?" A minha resposta: "se ter ideologia significa manifestar minha discordância sobre as situações de injustiça que as pessoas vivem, então eu tenho ideologia”. Assim, finalmente tive minha ficha limpa em 3 de maio de 1977, quando já estava quase findando meus prazos de completar a documentação no CNPq. Posso dizer que só obtive essa resposta quase 6 meses entre o depoimento e o atestado, graças à intermediação do ex-secretário do governo Triches, Dr. José Sperb Sanseverino, que atuava no Tribunal do Trabalho. Sua relação de amizade e consideração para com meu pai, através de afinidades políticas com o antigo PDC, fez com que se sensibilizasse pelo meu caso. Ele escreveu um bilhete ao secretário de segurança pedindo agilização no processo... bem, o ritual de me receberem com esse bilhete foi interessante. Deixaram-me numa sala 2x2, toda branca, sem janelas e só uma porta. Fiquei uns 15 a 20 minutos sem comunicação. E depois chegou um policial que me disse para aguardar o processo via protocolo geral. 
Esses episódios revelam bem o quanto uma simples política pública de concessão de bolsas de estudo pode se transformar em instrumento de arbitrariedade, quando manipulada, no seu cotidiano, numa instância tão micro como o Departamento de Operações da Polícia Social. Depois desses fatos estava liberado para seguir rumo a Stanford. Um dia talvez possa relatar, com detalhes, os fiascos que passei nesse longo trajeto entre Porto Alegre e San Francisco da Califórnia, como cidadão do interior fazendo pela primeira vez na vida uma viagem de avião!

\subsection{Minhas primeiras produções na academia: Economista ou Educador?}

A combinação entre essas duas áreas, economia e educação, já se constituía, aos poucos, através da produção dos trabalhos de conclusão: graduação (economia: implantação de um curso integrado, de $2^{\circ}$ grau, em Montenegro); Mestrado: Fatores determinantes para escolha de profissionais de alto nível, de local para morar a trabalhar.

A conclusão do meu curso de Ciências Econômicas exigia uma monografia, como já era professor desde 1969 e como esta era já minha definição de vida profissional, procurei aliar as duas coisas: foi um estudo de planejamento educacional, buscando uma racionalidade econômica, especialmente de custos, para a implantação de um curso de segundo grau numa cidade do interior de Montenegro -, onde três estabelecimentos de ensino da rede particular encontravam-se em situação de crise financeira. Foi um estudo clássico de apropriação de custos e de estudo de mercado (sobre o tipo de curso: clássico, científico ou técnico) e também relacionado com a sempre permanente vinculação com a continuidade dos estudos de seus egressos no $3^{\mathrm{o}} \mathrm{Grau}$ (em outras palavras, como também preparar para o vestibular). Foi um trabalho gratificante no qual contei com a colaboração de um amigo e colega, morador daquela cidade, que veio a falecer mais tarde, quando eu já estudava nos Estados Unidos. Aliás, vale aqui homenageá-lo e lembrar que, como economista, ele fazia uma viagem de avião de pequeno porte entre o RS e SC para o estudo de áreas em processo de assoreamento, e num acidente que o vitimizou. Meus familiares, aqui no Brasil, esconderam a notícia por um período de mais de 6 meses. Lembro que foi ele quem me deu forças durante o período do Dops, principalmente por suas qualidades de ser muito humano e, ao mesmo tempo, objetivo e calmo. Inclusive correu o risco de procurar informações nos assentamentos do serviço de segurança da ex-Sudesul, empresa que eu lutava para ser empregado depois de minha exclusão da SEC: ele encontrou "não" por cima do meu nome no processo e constatou que havia informes obtidos no Dops.

Ficava aí, nesse episódio, a determinação do magistério em minha carreira, uma vez que poderia ter sido transformado em especialista na área de $\mathrm{RH}$ numa empresa 
pública não fosse minha ideologia. Também me afastava da área de Planejamento da Educação em nível de Políticas Públicas, entretanto, levava-me a continuar nessa área em nível de Universidade também minha futura especialização, na área de concentração no mestrado: Planejamento Educacional.

Minha segunda produção: a dissertação de mestrado foi um dos exercícios mais monitorados que vivi. Foi um aprendizado clássico; mais do que eu, era o orientador que tinha interesse no tema, além do que representava o desafio de um planejador, um geógrafo americano que trabalhava no Propur, Mestrado em Planejamento Urbano da nossa UFRGS. Ambos fizeram com que eu escrevesse uma dissertação - viável - . Esse termo é o mais correto. Vivia-se um momento difícil de definições sobre aquilo que era possível numa sociedade brasileira cujo temor em tomar visível crenças políticas era uma força que condicionava nosso cotidiano. Uma das justificativas determinantes na escolha do tema foi poder usar referencial que ousasse citar autores como Celso Furtado.

De novo estava aí, na minha produção de conclusão de curso, uma combinação entre minha trajetória de economista e de educador! Foi interessante o exercício de fazer uma dissertação que atendesse as exigências da época: um tratamento estatístico sofisticado, especialmente baseado no princípio estatístico da "correlação" entre variáveis. Ora, no meu estudo estava lançado um avanço: mais do quo correlação, eu usava factor analysis que me ajudava a entender as possíveis combinações entre os diversos cursos de origem, idade, sexo e tipos de cidades que corresponderiam aos interesses dos estudantes de mestrado de 4 cursos da UFRGS. A possível incidência de uma política pública orientadora para alocar esses profissionais, mais em direção ao interior, fez com que eu pudesse escrever sobre o papel do Estado em desestimular as formas clássicas concentratórias do capital em torno de grandes capitais e próximas ao litoral... O que valeu nessa experiência foi trabalhar em conjunto com colegas, alunos de um mesmo orientador, e a aprender com certa rigidez o que pode ser uma dissertação de mestrado - em termos de prazos e de aprofundamento teórico. Valeu também para uma adequada apropriação das técnicas estatísticas e agora, mais tarde, poder relativar o seu uso, sem esquecer sua importância como um elemento síntese que ajuda no entendimento de fenômenos sociais. Na época, eu me tomei quase um assessor dos colegas e até de outros professores, devido à familiaridade que tinha com a Estatística, fruto de minha formação como economista. Lembro, por oportureola e de Neusa Armelini, Outra significativa contribuição do orienno, que ajudei, por exemplo, nos trabalhos dos colegas Balduíno Andtador de mestrado, Prof. Dr. Ray A. Chesterfield, foi entender, segundo ele, o tal jogo acadêmico: basta descobrir quais são as exigências dos editores das revistas internacionais, estudando um pouco a produção dos 
últimos anos e a composição do conselho editorial dessas publicações e você se encontra em condições de escrever artigos para todos e quase todos irão aceitar seus trabalhos. Foi assim que consegui ter minha primeira publicação internacional: com base na minha dissertação de mestrado escrevemos um artigo para a Holanda (Amsterdã), e lá está publicado. Fui compreender isso com mais detalhes nos Estados Unidos. Publique ou morra! E então se escreve a torto e a direito fazendo réplicas, tréplicas e tantas outras respostas sobre o mesmo tema por um período que pode ser infinito (enquanto houver alguém, do outro lado, para polemizar - aliás, polêmica que pode ser até previamente provocada para os dois lados acumularem artigos para seus currículos...).

\subsection{Doutorado: Engajamento e pesquisa}

A minha terceira produção foi e é o retrato de minha vida. É a minha cara. No seu início eu já dizia, em 1981, "This dissertation is part of my own life". Meu doutorado, por incrível que possa parecer, feito no exterior, tinha muito mais a minha trajetória existencial. Nos dois primeiros trabalhos eu fazia uma clássica combinarão entre economia a educação. Nesta eu revelava minha busca, que ainda hoje se constitui, de procurar entender as classes populares através também da compreensão do papel dos agentes de mediação: assessores, igrejas, partidos, universidades. Não foi fácil.

Eu fui aceito para estudar em Stanford, com a orientação do Carnoy, para um doutoramento que, em princípio, deveria continuar a conexão que fazia entre as áreas de minha formação: eu iria estudar economia da educação e, no empírico, estudaria as políticas educacionais e suas repercussões na área financeira/econômica, através das orientações emanadas do Conselho Estadual de Educação. Tentei. Mas depois de certo tempo, quase um ano e meio, e depois de mudar de orientador por duas vezes, escolhi finalmente o tema que definiu minha trajetória profissional, política e pessoal. Estudar a cultura das classes subalternas!

Foi assim que, sob a orientação de um professor visitante chamado Edmundo Fuenzalida, chileno, pude me dedicar a essa temática, Como seria quase impossível estudar isso - de longe - e com minha família procurando já sinalizar a necessidade de volta para o Brasil, é que resolvemos voltar para esta nossa terrinha e aqui permanecer mais de oito meses morando/vivendo numa comunidade urbana, de periferia, onde se constituía uma das primeiras ocupações na cidade de Canoas. Foi importante a conexão que tive com agentes da pastoral que atuavam nesse local; professor e Irmão Marista Antonio Cechin e sua irmã Matilde. Escrevi para eles desde os Estados Unidos perguntando da possibilidade de realização de um tipo de trabalho dessa natureza. Recebi uma resposta positiva, mas com um claro alerta: quem definirá isso serão os membros da 
comunidade da já denominada Vila Santo Operário, perto da Mathias Velho e do bairro Harmonia. Aceitei o repto e vim para esse trabalho. Foi, e ainda é, uma das experiências que mais me ajudam, aguçando a sensibilidade para compreender o processo cultural nos setores populares, desde a exigência em questionar certezas sobre teorias e métodos até as mais singelas trocas que se fazem no cotidiano. Vai aqui uma confissão. Poucas vezes disse isso. Minha pesquisa, do tipo etnográfico e participativo, foi feita sem leitura alguma a respeito de pesquisa participante. Brandão? Mal conhecia. Tinha uma fonte genuína em Freire e um misto de idealização sobre cultura(s) popular(es). Ao mesmo tempo, uma combinação com minha trajetória de católico, de inspiração na JUC e na AP.

Para mim, a escolha do tema de pesquisa e o referencial teórico estavam também revelando uma combinação entre o meu passado e as marcas do meu doutorado, onde tive o privilégio de encontrar colegas, professores que tinham o humano como dimensão essencial entre as questões teóricas.

Do meu passado lembro que, lá pelos idos de 19741975, quando Presidente do Conselho Municipal de Educação, em Novo Hamburgo, a pedido da primeira-dama, discutíamos políticas de não entrada de pessoas na cidade que viessem de outras regiões. Claro que isso era só para os pobres e trabalhadores. Na época, a cidade já começava a sinalizar com mudanças na sua estrutura de classe dominante: a exportação, de um lado, em franca expansão se combinava com a mudança do controle das lojas, empresas comerciais, daqueles primeiros empreendedores oriundos da região, era a época dos grandes magazines se espraiarem pelo interior. Com pouca discussão sobre quem eram esses setores das classes populares, a não ser que eram "de fora" e, portanto, estavam proibidos de entrarem no território dos migrantes alemães. Lembro que os meus primeiros passos para entender, via pesquisa, a cultura das classes populares, foram iniciados através de um trabalho de coleta de dados sobre uma população que tinha invadido uma nesga de terra, ao lado da Estação da CEEE; ainda existente hoje, ao lado da BR-116, do lado esquerdo de quem está chegando a Novo Hamburgo. Só que essa atividade foi feita num período desafiador que tive, na condição de diretor de uma escola comunitária, que tinha sido uma escola mantida pelos Maristas. Foi extremamente curiosa a reação dos alunos da $4 .{ }^{a}$ Série do ginásio, alunos e alunas, os quais, depois de voltarem do trabalho de campo, fizeram depoimentos num misto de ambiguidades: ficavam penalizados diante da miséria, mas ao mesmo tempo lembravam de seus hábitos de adolescentes de classe média, sempre preocupados com cardápios e roupas da moda.

Hoje observo que pouco tinha de base analítica para poder ir mais adiante nesse tipo de trabalho, ou seja, mesmo não sendo professor dos alunos, mas na condição de Diretor eu poderia ter proposto mais atividades 
relacionadas com a atividade e saindo de um tom um tanto moralista. Sei, pelo menos que, durante as discussões com a primeira-dama esse fato saiu da rotina da pauta que era somente a de encontrar os caminhos para, na madrugada, levarem os "diferentes" para longe.

A lembrança de como o eixo do meu trabalho foi se constituindo está, sem dúvida, na presença de um colega muito especial entre os americanos quo estudavam em Stanford. Trata-se do hoje professor o com textos traduzidos em português, Nicholas Burbules, o amigão Nick. Junto com ele lembro a parceria dos professores Arthuro Pacheco, representante da minoria chicana entre os docentes da Faculdade de Educação. Como professor do Departamento de Ciência Política, o mestre Charles Drekmeier deixou marcas muito fortes em mim. Com a combinação dos três, mais o aval do meu orientador Fuenzalida, pude fazer um trabalho de doutorado, nos Estados Unidos, sobre um tema eminentemente terceiro-mundista: as ocupações urbanas realizadas por populações do interior e dos sem-teto.

$\mathrm{Na}$ verdade, o que estes interlocutores fizeram foi fundamentalmente estabelecer um ritual de permanente acolhida. O Nick fazia, e faz ainda ho e, uma atenta leitura filosófica da obra do Paulo Freire. O lado acadêmico combinado com seu lado pessoal permitiu o estabelecimento de vários momentos de confidência, tanto sobre o tema de pesquisa como as intermináveis provas que um estudante estrangeiro tem que passar dentro da cultura americana. Pacheco, por sua vez, foi o latino que passou muito seu estilo de compreensão, permitindo-me com ele estabelecer laços pessoais. O apoio passava também por ter sido ele, por um período de dois anos, membro da equipe diretora da Faculdade, lá em Stanford, na função de Dean of Student Affairs, ou seja, ele me ajudou também a obter recursos para pagar meu tradutor, David Dye, o qual pasmem - refez minha tese em cinco versões a partir do meu inglês original! Com Drekmeier foi um misto de admiração pessoal e também profissional. Ele dava aulas sempre de pé, com suas permanentes sandálias, do tipo hippie dos anos sessenta, e os seus cabelos ainda meio longos contrastando com a figura de professor já com seus sessenta anos. Foi no seu curso: Hegemony, Authority and Legitimacy, onde eu pude pela primeira vez, fazer uma espécie de autoanálise, verificando como esses conceitos se constituíram na minha trajetória de vida. A receptividade do "Chas" foi total. Começamos a discutir os textos traduzidos em inglês do Rubem Alves e do Frei Betto. Afinal, perguntava ele, que história era essa que eu queria fazer com minha pesquisa em torno de uma comunidade eclesial de base. Foi então que ele começou a ler os tais textos e quando trocávamos ideias, ele associava Frei Betto a Harvey Cox.

Bem, daí dá para inferir como uma tese de doutorado pode ter conexões mais além do que a busca de credencial formal de um título acadêmico. No meu caso, com todos 
esses ganchos que ora faço, posso dizer que se trata de um exercício muito bonito, ligando vida a projetos de sociedade, de projeto humano, enfim. Os silêncios desse processo é que podem e devem ser trazidos para fora para que outros tantos trabalhos de doutorado, ou mesmo outras pesquisas, revelem melhor o que está sob a base constitutiva de uma produção científica.

\subsection{Pesquisa e assessorias em educação popular: a militância (sic) encontra seu desafio e exigência na atividade profissional}

Quem observar com atenção o tema dominante nos títulos das dissertações e teses por mim orientadas e mesmo das propostas (exames de qualificação), dentro e fora da UFRGS, vai perceber uma trajetória que contempla uma busca, permanente, em compreender as classes populares. É bem possível desenhar uma curva, desde o início de meus trabalhos, inclusive a própria tese de doutorado, onde o ponto de partida, da temática das classes populares, foi um privilegiamento de um olhar mais econômico/sociológico, no qual a escola desempenhava um papel importante, mas não central.

Aos poucos, através das próprias discussões dos pesquisadores nacionais, através de seus textos e mesmo de suas falas nos eventos científicos, a escola passou a integrar-se no cenário de forma mais parceira, tendo em vista a própria expansão das escolas públicas nos locais onde moram as populações dos ditos excluídos. Esse movimento fez com que também se desenvolvesse um processo mais cuidadoso em entender o fenômeno escolarização das classes populares como parte de um projeto de sociedade onde educação popular não fosse somente uma ação fora do Estado e, muito menos, clandestina. Esta mudança foi também me aproximando, com um profundo respeito, das teorias e propostas metodológicas vinculadas à contribuição da epistemologia genética, especialmente de Piaget e de diversos pesquisadores envolvidos com questões relacionadas à sala de aula, como o caso de Constance Kamii, Emilia Ferreiro, Sara Pain entre outros.

Essa mudança também se refletiu na outra área onde desenvolvo minhas investigações: educação e trabalho. É muito interessante fazer uma pequena reconstrução histórica sobre isso. Quando estava concluindo meu doutorado, em Stanford, especificamente em julho de 1981, quando fui sozinho, sem a família, para concluir a tese, encontrei Miguel Arroyo pela primeira vez. Deu para estabelecer de imediato uma relação saudável, tendo em vista uma simpatia pessoal e o interesse pelo campo comum de pesquisa. Acompanhei o final de sua tese e depois, já no Brasil, procurei avidamente entender como ele tinha feito seu estudo histórico em torno do eixo: educação e formação da classe operária no Brasil. Foi também, pela primeira vez, que me deparei com a contribuição criativa, competente e sensí- 
vel de Edward P. Thompson, através de sua obra The Making of the English Working Class. Daí tudo se combinou: uma curiosidade pessoal pelo resgate histórico que sempre me desafiava - as classes subalternas. Saía de uma visão só descritiva e talvez ate nostálgica sobre os pobres (e, por obséquio, vejam pelo menos os dois fatos narrados por mim antes: as leituras de Lebret lá na casa do meu avô em Lajeado... e as ações de pesquisa desenvolvidas na escola em que eu era diretor). O Thompson faz a combinação harmoniosa de um historiador de matriz claramente marxista com a antropologia, através do estudo das experiências de uma classe em formação, isto é, do seu vivido e daí busca apoio num referencial teorico clássico. Por meio dessa interdisciplinaridade se consegue dar uma ressignificação ao conceito de classe social fora dos esquemas estrutualistas. Nesse movimento, ele se aproxima do mesmo processo que Francisco de Oliveira (do Ceprab) faz com identico referencial teorico sobre o também polêmico conceito de classe social (vide seu livro O Elo Perdido, no qual estuda e aplica essa base teórica num estudo sobre as classes subalternas em Salvador, BA).

Ora, uma combinação entre educação popular e educação e trabalho, passando por esse referencial dava oportunidade para que minhas pesquisas se dirigissem a esse mesmo processo de buscar, no dado empírico, via análise de documentos e fontes em jornais e publicações oficiais, uma compreensão de como, aqui no RS, se processou a formação dessa classe. Na pesquisa desenvolvida com o apoio do Inep (bem se sabe o que significa o Inep ajudar financeiramente o pesquisador: pouquíssimos recursos, com liberação sempre atrasada e num país inflacionário, o recurso só serve para pagar as despesas de correio), pretende-se aplicar esse referencial para compreender como, nos primeiros trinta anos deste século, as políticas públicas - através de escolas noturnas para crianças e adolescentes trabalhadores da capina de rua, serviram para formar esse segmento da população.

Também pesquisas com a mesma preocupação teórico-metodológica foram patrocinadas pelo CNPq, através de bolsa de estudo para mim e para bolsistas de aperfeiçoamento a de Iniciação Científica. Estou agora na $3 \cdot^{\mathrm{a}}$ etapa e também com um pedido novo de Projeto Modalidade AI, no qual pretendo trabalhar em conjunto com professores-pesquisadores da Unisinos e da PUC/RS, seguindo, em parte, a nova política de apoio integrado. A contribuição da hoje doutoranda no PPG-EDU, Maria Stophanou, foi absolutamente decisiva em me ajustar a um processo de ser pesquisador com a ênfase nesse estudo de documentos. Destaco sua experiência de historiadora e seu hábil manejo com a organização e o fichamento de documentos. Isso foi decisivo para que as auxiliares de pesquisa se tornassem extremamente competentes nas suas idas aos locais onde os documentos estão arquivados. Dentro dessa perspectiva teórico-metodológica sinto-me desafiado pela dimensão 
histórica e curioso em compreender as relações entre educação e classes populares a partir da educação popular e do binômio educação-trabalho.

Hoje, com a divulgação de autores relacionados com a denominada Nova História, especialmente as contribuições de Peter Burke, podemos encontrar as inter-relações entre história, sociologia e antropologia. E, dessa perspectiva, buscando apoio em Thompson e Hobsbwan, é possível trazer saudáveis aproximações com a educação tanto nos territórios institucionais como fora deles, para que ações sejam desencadeadas no sentido da superação de processo de exclusão social (via evasão à repetência) e ao mesmo tempo ampliar os mecanismos da compreensão sobre esse permanente desafio de entender a relação do homem com o mundo em que vive.

No momento do exame da produção intelectual vou apresentar um projeto com essa perspectiva. Mais precisamente vou desenvolver, entre esta data de entrega dos documentos (13/10) até o momento do concurso, um projeto de pesquisa que inclui essa trajetória, brevemente descrita acima, aliada à minha atual assessoria (voluntária) para com as Mulheres Papeleiras que trabalham nos galpões situados na periferia de Porto Alegre, bem como no Conselho Municipal dos Direitos da Criança e do Adolescente. Em ambas as situações, mais uma vez aparecem os desafios antepostos pelas temáticas: educação popular e educação a trabalho. O que tem de novo nessas atividades é: a perspectiva de que tais ações gerem renda para os que nelas trabalhem e com isso se possa entrar em contato com agentes de mediação, a fim de que essas atividades não desapareçam tão facilmente por falta de um planejamento com essas populações e instâncias do Estado (Estado e Município), dos Partidos, das Igrejas, das Universidades e, por paradoxal, com o Mercado. Esse projeto se refere especificamente ao processo educativo que tanto mulheres papeleiras como crianças (com mais de 14 anos) e adolescentes estão passando para superarem aqueles projetos de cunho assistencialista, tanto de entidades caritativas como do Estado populista.

Presentemente, nas atividades de assessoria que realizo, posso identificar elementos que corroboram as reflexões do sociólogo paulista e assessor da CPT, Jose de Souza Martins. Ele tem sido extremamente crítico a respeito do papel mediador que realizam as representantes das instituições acima descritas. Por tudo isso e, fazendo um exame dos passos dados nesses 47 anos de vida - mais especificamente os sonhos desenvolvidos na adolescência em querer resolver o problema de transporte dos trabalhadores das fábricas em Novo Hamburgo, passando por leituras que me foram muito caras, misturando a formação católica e as aproximações marxianas, mais as assessorias hoje em desenvolvimento - dá pra entender não só a escolha de pesquisa feita para o doutorado como as que realizo atualmente na condição de bolsista do CNPq: um processo 
continuado em buscar compreender com as pessoas que se localizam na esfera da exclusão podem ser desencadeadoras de mudanças entre aqueles, como eu, que desejam contribuir para a superação de desigualdades.

Confesso que me sinto muito confortável com as recentes análises que Francisco Weffort vem realizando a respeito da sociedade brasileira, quer do ponto de vista da política, quer do ponto mais crucial da realidade econômica. Não há como nós procurarmos, todos, indistintamente de área de conhecimento, provocar estudos e ações em direção de uma sociedade democrática. Aliás, essa proposta teve tantos desgastes em nossa recente história que a própria esquerda clássica procura postergar tal discussão para sempre depois quando as famosas condições objetivas estivessem resolvidas. Só então se poderia enfrentar esse desafio concretamente. Não só os muros caíram para desautorizar esse tipo de simbolismo. Houve também um processo desruptor, criado no interior de cada um de nós, de cada corpo que sinalizava as incompletudes de tais macrossoluções. Aliás, talvez algumas reflexões em torno da Ética poderiam ser contundentemente feitas, relacionadas com as relações entre homem-natureza, para desmanchar essa lógica predatória que se constitui nessa visão antropocêntrica, que tudo justifica em nome de um processo de acumulação capitalista/privada, provocando situações limite de uma sobrevivência humana digna. A educação também se encontra aí, nessa discussão. Minhas pesquisas e a produção científica que entrego para exame procuram enfatizar essa preocupação de fundo, a partir daquilo que a educação pode e deve fazer.

\subsection{O afetivo transformador dos territórios privado e público}

Em minhas falas, tanto em eventos científicos quanto em encontros mais informais, costumo fazer um depoimento no qual tento traduzir um pouco a síntese que faço entre meus processos de ordem pessoal e aqueles que poderiam ser classificados como mais relacionados à macrossociedade. Aqui também, encerrando estas reflexões desejo discorrer um pouco a respeito destas nuances que, sem pedir licença, vão compondo o quadro da minha vida.

De um lado, como trajetória pessoal constato que, aos 47 anos, e em 1995 completando 25 anos de casamento com a Beatriz, algumas coisas muito boas aconteceram comigo. De cara digo que a presença cotidiana da Beatriz foi decisiva na construção dessa relação de positividade com o mundo. No espaço doméstico, do dia a dia de pai e companheiro é possível, com alguns tropeços, claro (e nesse aspecto o Gustavo e a Janaina podem atestar como isso acontece concretamente), ir montando esse xadrez de (com)vivências, aumentando o sentido de estar peregrino por estes territórios... No espaço público como profissional em atuação, conforme o curriculum vitae atesta e minhas 
reflexões acima também sinalizam, é possível estar em atitude de sintonia com os mais diversos e complexos processos que nos estão educando constantemente.

Talvez seja interessante lembrar aqui de uma pessoa quo muito contribuiu para que eu expressasse sentimentos: Rubem Alves. Ele sabe disso, pois já fiz esta declaração ao lado dele, publicamente, quando integrávamos um painel para dezenas de professores. Declarei que, a partir de seus textos, eu me autorizava a falar mais desse processo interno, com o qual estamos em permanente diálogo, para os outros, com os outros. Claro que não é um processo fácil e muito menos um processo de colocar a ego na vitrine. Trata-se, outrossim, de um desejo que os outros, na interlocução, façam o mesmo. Por isso o título desta parte final do memorial: um público e um privado em trocas, em simbiose!

Mas se esses múltiplos processos estão em ebulição, eles não estão dissociados de outro privilégio que considero estar vivendo: a produção científica na área da educação em dimensão interdisciplinar. O que isso significa? Para mim a tradução é a seguinte: o próprio campo específico da educação necessita de constante interlocução com outras áreas do conhecimento. Parece simples, mas as minhas experiências com colegas da sociologia, da filosofia, da antropologia, da história, da psicologia - e em especial minha área de origem, a economia - têm trazido riquezas enormes em forma de contribuições decisivas para a compreensão do nosso fazer. Antes de ir adiante quero afirmar que esta atitude interdisciplinar supõe um genuíno processo afetivo de querer, de desejar, de provocar essa interdependência. Considero importante o testemunho que pesquisadores da nossa Área fazem quando efetuam relações com outras áreas de forma criativa. Mas confesso que fico mais alegre quando tais aproximações (diria seduções, posso?) estão conectadas com situações-problema que a prática desafia. Quando antes escrevia sobre minha experiência na Secretaria Municipal de Educação de Porto Alegre, eu estava sem dúvida subsidiado par essa relação dinâmica da teoria-prática, nessa perspectiva interdisciplinar. Há tempos atrás, quantas e quantas vezes se fizeram analises simplificadoras, como muito bem Miguel Arroyo critica em seu artigo sobre a escola possível para as classes populares, discorrendo sobre a contribuição da psicologia para demonstrar, cientificamente, que a responsabilidade (portanto, a culpa) pelo fracasso escolar era do próprio aluno e, quiçá, da sua família.

Ou seja, a psicologia entrava muitas vezes não para ajudar a entender a complexidade do ato educativo, mas pelo contrário, para justificar a processo de exclusão! Não vou ampliar as inúmeras formas equivocadas que outras áreas também trouxeram para a educação. $\mathrm{Na}$ verdade o que faltava quase sempre era uma solidária abordagem interdisciplinar. O que hoje temos é uma retomada, por exemplo, daquilo que Freire prega sempre - o diálogo - e 
que autores como Habermas transferem ampliando para o significado do ato comunicativo como agente provocador da construção de uma sociedade democrática. Ora, as propostas podem e devem criar situações para que tais amplificações, abrangências, envolvam o cotidiano de cada professor e em cada escola.

Gostaria de escrever mais sobre essa atitude receptiva que a educação está tendo com outros campos do conhecimento. Seria importante, em outro tipo de trabalho, trazer elementos que ajudassem no entendimento de algumas ondas, ditas pós-modernas, as quais estão pairando, tal como nuvens acima do terreno da educação. Em relação ao propósito deste último item, quero fazer uma leitura mais atenta das razões dessa onda, pelo menos aqui no Sul, na nossa Faced. Num primeiro momento sinto que a insuficiência de aprofundamento teórico de outras modas pelas quais a educação passou, do tipo: conscientização(Freire), reprodução (Bourdieu), construtivismo (Piaget), entre outras demonstram, de um lado, uma avidez por novidades combinada, por outro lado, com uma atitude consumista negadora da reflexão que tem o tempo como aliado. Por que relaciono isso com o público e o privado, neste espaço do afetivo? Parto da hipótese segundo a qual os mecanismos de apoio para o equilíbrio cotidiano, tanto no terreno pessoal como no profissional, buscados de fora, sem mediações do próprio sujeito, ajudam a construir uma casca que esconde um terreno extremamente fértil e, ao mesmo tempo, vulnerável do sujeito incompleto.

Ouso afirmar que os textos sobre micropolítica do desejo - para pegar os termos do título do livro do Guattari - constituem uma vertente possível de ser aprofundada, aliando-se rigor teórico e subjetividade, abordagem esta feita muito apropriadamente dentro da academia (PUC-SP) pela psicóloga brasileira, Suelv Rolnik. Tenho convicção da necessidade dessas abordagens entrarem na cena onde se desenvolve nosso gesto cotidiano de educadores.

Assim, poderíamos compreender melhor como, em menos de 30 anos, nossa área soube passar de um polo quase sem sujeito, o polo das grandes determinações materiais, para chegar a outro, desvelando a presença desse sujeito, o qual não vira suas costas para essa necessária leitura histórico-estrutural. O polo que compreende a ação do sujeito inteiro e inteirado, elemento indispensável em dinamicamente desvelar as relações entre o privado e o público. Para mim, o terreno da diversidade se constrói justamente na não separação desses campos, permitindo um profundo respeito aos processos de cada sujeito, os quais colocados em situações que se sucedem, enraizadas simultaneamente em projetos de construção de uma sociedade mais humana e democrática.

Para concluir este memorial aproveito a oportunidade para fazer uma pequena homenagem ao filósofo, o qual tive o privilégio de conhecer durante a XV Reunião Anual da Anped: Jose Américo Motta Pessanha. Suas palavras, 
conforme página 29, Cadernos da Anped, n. 4, de setembro de 1993, me ajudam na síntese das reflexões até aqui feitas: enquanto a verdade absoluta, ahistórica e atemporal pretende organizar-se de forma unívoca, de uma vez por todas e para sempre, a razão do tipo dialógico inerente ao discurso natural se constrói e se reconstrói numa permanente abertura. Isso dá uma dimensão muito maior à ciência e recoloca uma série de questões sob nova luz!

Porto Alegre, 13 de outubro de 1993. 